\title{
Mitigating energy demand sector emissions: The integrated modelling perspective
}

\author{
O.Y. Edelenbosch ${ }^{\mathrm{a}, \mathrm{b}, *}$, D.P. van Vuuren ${ }^{\mathrm{a}, \mathrm{c}}$, K. Blok ${ }^{\mathrm{d}}$, K. Calvin ${ }^{\mathrm{e}}$, S. Fujimori ${ }^{\mathrm{f}, \mathrm{g}}$ \\ ${ }^{a}$ PBL Netherlands Environmental Assessment Agency, Bezuidenhoutseweg 30, 2594 AV Den Haag, the Netherlands \\ ${ }^{\mathrm{b}}$ Department of Management and Economics, Politecnico di Milan, Via Lambruschini 4/B, Milan, Italy

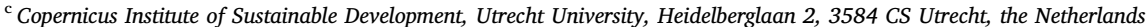 \\ ${ }^{\mathrm{d}}$ Faculty of Technology, Policy and Management, Delft University of Technology, Jaffalaan 5, 2628 BX Delft, the Netherlands \\ ${ }^{\text {e }}$ Pacific Northwest National Laboratory 5825 University Research Court, Suite 3500, College Park, MD 20740, USA \\ ${ }^{\mathrm{f}}$ Department of Environmental Engineering, Kyoto University, 361, C1-3, Kyoto University Katsura Campus, Nishikyo-ku, Kyoto-city, 615-8540 Japan \\ ${ }^{\mathrm{g}}$ Center for Social and Environmental Systems Research, National Institute for Environmental Studies, 16-2 Onogawa, Tsukuba, Ibaraki 305-8506, Japan
}

\section{H I G H L I G H T S}

- Global baseline emissions can grow rapidly in industry and transport sectors.

- A key uncertainty across models and scenarios is projected final energy per capita.

- The technology assessment shows more efficiency potential for buildings and transport in the short term.

\section{A R T I C L E I N F O}

\section{Keywords:}

Global scenarios

Energy efficiency

Demand sectors

Shared socioeconomic pathways

\begin{abstract}
A B S T R A C T
Limiting climate change below a given temperature will require fundamental changes in the current energy system, both in the energy supply and the energy demand sectors. Previous global model-based analyses, however, have focused mostly on energy supply transformations. Therefore, in this study we respond to this knowledge gap by analysing the future energy demand projections in both baseline and climate policy scenarios of global models in detail. We examine the projections for the industry, transport and buildings sectors across four models and three different reference scenarios from the Shared-Socioeconomic Pathway framework by applying a decomposition analysis. We compare the projected demand side mitigation efforts to a more detailed, sector-specific, technology-oriented assessment of demand-side abatement potential for the year 2030. Without climate policy, model-based projections show that baseline emissions can grow rapidly in industry and transport sectors, but are also highly uncertain across models. The decomposition analysis shows that the key uncertainty across the global scenarios is the projected final energy per capita. For modellers therefore there lies a challenge to better understand drivers of future energy efficiency and service demand, that contribute to the projected energy demand. This model enhancement would moreover allow to evaluate policy measures that can impact this relation. The technology assessment estimates that in particular in the transport and buildings sector there is a higher potential to reduce demand-side emissions through energy efficiency improvements than implemented in the scenarios. Improved insulation, higher electric vehicle penetration rates and modal shift for example could reduce final energy demand to lower levels in the short term than currently projected, reducing the dependency on fuel switching required in current scenarios to meet the stringent climate targets.
\end{abstract}

\section{Introduction}

Model-based analysis is used frequently to analyze future trends in the energy system and to explore the implications of mitigation strategies at the global level. The models used for this include energy system models, integrated assessment models (IAMs) and macro-economic models. Traditionally, these models focus mostly on energy supply sectors [1]. Indeed, decarbonizing energy supply by switching to low carbon energy supply technologies (renewable energy sources, nuclear power or applying carbon, capture and storage), can be an

\footnotetext{
* Corresponding author.

E-mail addresses: Oreane.Edelenbosch@pbl.nl (O.Y. Edelenbosch), Detlef.vanvuuren@pbl.nl (D.P. van Vuuren).
} 
effective strategy to mitigate greenhouse gas emissions $[2,3]$. However, more than half of the energy related greenhouse gas (GHG) emissions directly ${ }^{1}$ currently occur in the energy demand sectors, i.e. buildings, transport and industry sectors [4]. To achieve stringent climate targets, such as those aimed for by the Paris agreement, requires reducing all energy system emissions towards zero before the end of the century [5], therefore energy demand emissions will have to be cut drastically as well [6]. Direct emissions do not provide the full representation of the importance of these sector as they also indirectly drive the supply side emissions and the amount of primary energy used. Additionally, energy demand policies can have important co-benefits, such as improving energy security and reducing environmental pollution $[7,8]$. Understanding how these sectors will need to change in a climate constrained world is so far insufficiently assessed in global long-term projections [9].

A key reason why models have focused more on energy supply than demand, is that there is a high level of diversity and complexity within the demand sectors. Compared to more detailed sector-specific tools, the advantage of IAMs is that they offer a system level perspective on climate change mitigation pathways with interactions across sectors. However, within this broad perspective, the modellers are faced with a choice to either include many functions and technologies, that could lose meaning over the centurial timeframe, and at the costs of transparency, or include a more stylized representation of energy demand [10]. The latter has clear advantages, and could potentially represent the overall sector behaviour well, but is less easy to relate to tangible mitigation measures. Moreover, the impact of emerging phenomena that break with historical trends, such as innovative technologies, are difficult to evaluate.

Sugiyama et al. [11] show that across a set of 18 IAMs energy intensity declines in response to climate policy, but the significance of this effect differs widely across models. Yet the underlying reason behind such a wide divergence was not explained. Also, Marangoni et al. [12] show that across the recently developed Shared Socio-economic Pathways (SSPs) energy intensity and economic growth are the most important determinants of future carbon emissions from the energy system, both with and without a climate policy. Thus, while energy demand and energy efficiency plays a key role in IAM future climate projections, their development is uncertain and within their aggregated representation the translation of the model results to policy instruments is not straightforward. Given the importance of integrated energysystem models in advising policy-makers, a better understanding of what these models currently say with respect to future energy demand developments is needed.

In this study, therefore, the aim is to provide transparency on the projected demand sector changes, by analysing IAM future energy demand projections in more detail. We compare not only different models but also different demand sectors and different storylines. The recently developed Shared Socio-economic Pathways (SSPS) provide a unique set of consistent socio-economic developments to discuss possible trends across demand sectors under different assumptions, in scenarios with and without climate policy $[13,14]$. While several IAM comparisons have been performed at the sector level, comparing for example transport [15], industry [16], and the power sector [17], there has not been a cross-demand sector model comparison of this level of detail yet.

The data is disentangled through decomposition analysis to allow for a consistent method to assess the projections across the diversity of approaches between models and sectors. The projected carbon dioxide emissions of the three largest energy demand sectors (buildings, industry and transport) are allocated to changes in population, final energy per capita, electrification and fuel switching. In addition, the

\footnotetext{
${ }^{1}$ If emissions are allocated to the sector where they physically take place, which is the common approach used in IAMs.
}

energy service ${ }^{2}$ and energy efficiency change are analysed of the relatively technology-rich IMAGE and GCAM models. Finally, to improve the comparison with the more detailed sector studies, the model results are compared to a recent analysis containing a sector-specific technology-oriented assessment of abatement potential in 2030 to reduce demand sector emissions.

\section{Background}

IAMs tend to focus analyses more on mitigation of energy supply side emissions, while relatively less attention has gone to the use of energy and the role of energy reduction in a global setting to achieve climate targets. Generally, the energy supply sector is also represented with more detail in IAMs and energy system models than the energy demand sectors [10].

There are several key reasons for this:

- Energy demand sectors are highly diverse, with many sub-sectors, different functions for which energy is used, technologies and users making these sectors more difficult to describe by models. These different users moreover vary in their preferences and needs.

- There is a faster turnover of capital stock and innovation cycles in the energy demand sector than in the energy supply sector, which adds to the sectors complexity.

- The rules affecting future energy demand change are less defined, as actors use many more criteria in making decisions than the "rational" cost-optimization to investment decisions that are typically used in the energy supply sector [19].

Therefore, models, in contrast, often use a more a very aggregated description to represent energy demand, relating demand directly to aggregated economic and demographic scenario drivers, based on historical trends, and a stylized representations of efficiency change. Recently, however, more details, especially in the transport sector, have been added [11]. Within the global decadal scope of IAMs including more details does not necessarily improve accuracy, as over the longterm uncertainties increase.

The focus on aggregated regions and sectors can limit the models' ability to represent the full complexity of the demand sectors [20], or short term and existing policies at the national or sub-national level, making the results less tangible for policy makers. However recently several research efforts to bridge the gap between global long-term models and regional short term policy are made [21,22]. There are many energy demand assessment of mitigation opportunities performed at urban, regional and national scales. Combining information streams of models with different levels of integration is important and ensures to make use strengths of models with different characteristics [10].

Bottom-up technological studies emphasize the potential of energy efficiency to mitigate climate change. Also, the recent IPCC $1.5{ }^{\circ} \mathrm{C}$ report states the importance of demand side changes to enhance the probability of limiting global temperature rise to $1.5{ }^{\circ} \mathrm{C}$ [5]. Often technologies are readily available, such as electric vehicles, or near zero buildings, which provides the opportunity to reduce emissions already in the short term. However, the demand sector is also characterized by many users, technologies, and structures (such as buildings), which increases the effort to have this transition take place. It would not require one person to adopt an electric vehicle, but a whole nation. Opportunities to improve energy efficiency in the buildings sector lie in thermal characteristics of insulation in walls, roofs, and windows [23]. While paying attention to energy efficiency when designing a building can save time and money compared to retrofitting existing buildings,

\footnotetext{
${ }^{2}$ Energy service here refers to the human activity obtained through the use of energy and to satisfy a human need [18]. For example, referring to mobility, lighting, heating, industrial products such as steel or cement.
} 
Table 1

Model characteristics [34,32].

\begin{tabular}{|c|c|c|c|c|}
\hline Model & AIM/CGE & GCAM & IMAGE 3.0 & MESSAGE-GLOBOIM \\
\hline Solution method & Recursive dynamic & Recursive dynamic & Recursive dynamic & Intertemporal optimization \\
\hline Model category & General Equilibrium (GE) & Partial equilibrium (PE) & $\begin{array}{l}\text { Hybrid (systems dynamic model and GE for } \\
\text { agriculture) }\end{array}$ & $\begin{array}{l}\text { Hybrid (systems engineering partial equilibrium linked to } \\
\text { aggregated GE) }\end{array}$ \\
\hline Hosting institute & NIES & PNNL & PBL & IIASA \\
\hline SSP reference & [42] & [43] & [44] & {$[45]$} \\
\hline
\end{tabular}

without retrofitting the speed of an efficiency transition in this sector will be strongly slowed down given the long lifetime of buildings [24]. In the transport sector switching to electric cars could be an attractive strategy to reduce GHG emissions, if electricity is generated by low carbon fuels, while electrification of air transport and freight are less obvious choices due to battery requirements and costs [25]. Freight energy efficiency options in shipping, as well as road freight has been emphasized. Urban transport experts, in contrast, emphasize the importance of compact urban development, rapid bus transit, bicycle highways and telecommuting to mitigate transport emissions the so called avoid and shift strategies [26]. Besides adopting more efficient technologies, in the industry sector there are a broad set of additional mitigation options. Examples are changing material use efficiency, material recycling and re-use of materials and products, product service efficiency (e.g. longer life for products) or activity reduction (e.g. less product demand) $[27,28]$. The potentials here will differ per type of product, vehicle or material used.

The consequence of the aggregated representation of energy demand developments in IAMs is first of all that the comparison between demand sector changes anticipated by the models and tangible mitigation measures such as discussed in the previous paragraph is not straightforward. In this study by decomposing the IAM demand sector projections and comparing results to a technology oriented literature assessment we aim to bridge this gap. Secondly, although significant potential of behavior change to reduce energy demand is identified $[29,30]$, the stylized modelling approach has resulted in this component not well understood [31]. The SSP scenarios used here illustrate different world ranging from more sustainable behavior to a less corporation oriented world (see below).

\section{Methods}

\subsection{Scenarios used}

The SSPs together form a scenario framework in which future radiative forcing levels, affecting climate change, are combined with alternative pathways of socioeconomic development. The scenario framework is recently developed by the climate change community and the scenario assumptions and key outputs have been described in detail in special issue in Global Environmental Change [32]. Varying trends in key factors affecting climate change, such as population dynamics, economic growth, technological change, social, cultural and institutional changes and policies, have been combined into five consistent and plausible narratives, or reference scenarios, (SSP1 to SSP5) [33]. Comparing models that share common narrative assumptions on socioeconomic trends has as advantage that they are more comparable than those that do not. By using the SSP framework we can therefore distinguish across model and scenario agreements and uncertainties.

The scenarios differ in their climate change mitigation and adaptation challenge, due to varying reference emissions in the absence of climate policy as well as the projected "mitigative and/or adaptative capacity" of the projected future society. In this study the scenarios SSP1, SSP2 and SSP3 are compared, that span the range from low to high "mitigative and adaptative capacity". The three scenarios are "reference pathways" in which no climate change, climate impacts or new climate policies are assumed. SSP1 explores a story in which society is oriented towards a more sustainable development. This is translated into assumptions on rapid technological change directed toward environmental friendly purposes, lessened inequalities, educational and health investments, resulting in relatively low population growth and high land productivity. SSP3 is the opposite of SSP1 with moderate economic growth, rapidly growing population, regional conflicts pushing countries to focus on regional issues, slow technological change especially in the energy sector, low investment in human capital and inequality. SSP2 is the "middle of the road" scenario and forms the intermediate case between SSP1 and SSP3 [13].

Based on these narratives a common set of inputs were developed to guide the quantitative interpretation of the scenarios, which have been adopted by multiple IAMs. To analyse the sectoral emission reduction potential, SSP1 and SSP2 reference scenario are compared to its mitigation scenario in which the nominal RCP forcing level $2.6 \mathrm{~W} / \mathrm{m}^{2}$ in 2100 is met - in line with $66 \%$ chance of keeping the increase in the global average temperature below $2{ }^{\circ} \mathrm{C}$ above pre-industrial levels [32]. Since not all models were able to meet $2.6 \mathrm{~W} / \mathrm{m}^{2}$ in a SSP3 world, additionally the three scenarios are compared with a forcing level of $3.4 \mathrm{~W} / \mathrm{m}^{2}$, which corresponds roughly with $20-40 \%$ chance to stay below $2{ }^{\circ} \mathrm{C}$.

\subsection{Models}

In this study, we use the results of four IAM models (out of a total of six quantifying the SSP scenarios) i.e. those models that distinguish between all demand sectors separately. These IAMs are AIM/CGE, GCAM, IMAGE and MESSAGE-GLOBIOM. AIM/CGE is a general equilibrium model, GCAM partial equilibrium and IMAGE and MESSAGEGLOBIOM are hybrid models. While the first three have a recursive dynamic solution algorithm, MESSAGE-GLOBIOM is an intertemporal optimization model (see Table 1) [32]. We have excluded two IAMs, REMIND and WITCH, because the versions used to generate the SSPs did not distinguish enough sectors in energy demand. Below the specific demand sector description for each of the four models are discussed in more detail.

\subsection{Demand sector representation in the models}

\subsubsection{Buildings}

GCAM, IMAGE and AIM/CGE have split the demand for the residential sector from the demand for the commercial sector, while MESSAGE-GLOBIOM models the commercial and residential sector as a whole [34]. IMAGE specifies for the residential sector the demand appliances, space heating, water heating, space cooling which all can be fulfilled by different technologies. In MESSAGE-GLOBIOM the demand for thermal and specific (using only electricity) is defined, and GCAM the use of heating, cooling and other are specified for both sectors. In AIM/CGE, which is of the four models the more top-down, or macroeconomic based, household energy consumption is determined by a linear expenditure function. In this function, the population drives the subsistence consumption, while a structural change parameter, namely the marginal share of consumption, determines how this money is spend. A logit type function divides the energy fuel mix but end-use technologies are not explicitly included.

In IMAGE and GCAM floor space and heating degree days drive the 
heating and cooling service demand, which satiates at a certain level of GDP. Buildings technologies are assumed to improve over time and in both models are distributed by a logit function. If fuel prices increase, as a result of for example resource scarcity or a carbon tax, alternative fuels or efficient technologies will become more attractive. GCAM also includes building shell conductivity as a technology which is not explicitly included in IMAGE $[35,36]$. In MESSAGE-GLOBIOM fuel switching is the main option, where different fuels are associated with different relative efficiencies.

\subsubsection{Transport}

Generally speaking, the transport sector is described with more detail than other energy demand sectors in IAMs, which is discussed in [15]. In GCAM, MESSAGE-GLOBIOM and IMAGE different transport modes are distinguished within the passenger and freight transport sectors. All three models also make use of the concept of travel time to include the value of the modal speed, which leads to adoption of higher speed modes with increasing income. GCAM, in addition, distinguishes between long-distance passenger air travel, international freight shipping as different types of demand. The cost of transport technologies for each mode depend on fuel prices, technology costs, load factors, vehicle use which vary over time and regions. In AIM/CGE the car energy demand is calculated in a similar manner to the residential consumption, while the rest of transport is included in the production sector and determined by a constant elasticity of substitution function. Here energy and value added are assumed to have a substitutional relationship. Besides this relationship, energy demand is affected by technological progress, linked to GDP growth, and by energy prices. Technologies are in the case of AIM/CGE not explicitly modelled [34].

\subsubsection{Industry}

In MESSAGE-GLOBIOM, similar to the residential sector, the industrial sector distinguishes between the thermal and specific demand. The industry sector is modelled as a whole, without a specific representation of industrial subsectors. In GCAM apart from cement and fertilizer demand no specific industrial uses of energy are accounted for, where the industrial sector is represented as a generic demand for energy services and feedstocks. There is cost-based competition between fuels, with a low elasticity of substitution since specific uses of the energy are not specified. In IMAGE the iron and steel sector as well as the cement sector are explicitly modelled including service demand, a suit of technologies to produce these industrial goods, and specific mitigation measures such as clinker substitution [36]. The rest of the industry is modelled in a more stylized way where energy efficiency responds to autonomous and price induced improvements, fuels are substituted based on costs. In AIM/CGE the industry sector is modelled similar to the other production sectors described above.

\subsection{Decomposition}

We use a decomposition method to analyse trends in energy demand, in particular to identify the role of the different strategies for GHG reduction discussed in the introduction. There are several decomposition methods, broadly categorized in the Laspeyres based methods and the Divisia based method. The simple Laspeyres decomposition method calculates the change in emissions if one factor would change while all others would stay at their base year value. Although the interpretation is easy, the summation of all factor contributions do not equal the total emission change. Here we use the Shapley/Sun method, which is based on the Laspeyres method, but leaving no residual term. Leaving no residual term means that the factor contribution to the actual emission change is calculated. In a low emission scenario, the growth of population, for example, will have a smaller effect than the same population growth in a high emission scenario. Similarly, final energy growth has a larger effect when carbon intensive fuels are used. As a consequence, the same factor change will have a different impact in different scenarios. When comparing the decomposition analysis across scenarios, a larger or smaller factor contribution therefore cannot directly be interpreted as the factor itself being larger. It means that within the context of that scenario its contribution is more important. The Shapley/Sun method also passes the factor and time reversal test, and it solves for negative emissions, unlike the Divisia method [37].

Through index decomposition analysis the contribution of the projected change in the following elements to the direct sectoral carbon emissions are calculated:

(1) Population growth (Pop)

(2) Final energy use (FE) per capita

(3) Electricity and hydrogen use (Elec) share

(4) Direct emissions of non electric fuels.

Each of these elements contribute to the sectors' direct emissions following Eq. (1).

Direct emissions $=$ Pop $* \frac{F E}{P o p} * \frac{1-\text { Elec }}{F E} * \frac{\text { Direct emissions }}{1-\text { Elec }}$
with $\frac{F E}{P o p}=\frac{\text { Energy service demand }}{\text { pop }} * \frac{F E}{\text { Energy service demand }}$

The focus is on direct emissions, therefore, the indirect emissions of electricity production are not accounted for. Previous model comparison studies have shown by 2030 the carbon intensity of the electricity sector would need to be about approximately half of 2010 emissions while by mid-century it would need to be close to carbon free when aiming for a $2{ }^{\circ} \mathrm{C}$ target [6]. The final energy per capita development of the GCAM and IMAGE is further decomposed in to change in energy service demand and energy efficiency improvements following Eq. (2) in buildings, passenger and freight transport. The building floor space, passenger and freight kilometres travelled are used as proxies for the respectively transport and buildings energy service (i.e., activity levels).

\subsection{Technology-oriented assessment}

Technology-oriented studies look at sectoral greenhouse gas emission reduction potentials as well, also referred to as bottom-up potentials. A recent study, which is also part of the UNEP GAP 2017 report, focusses on the global mitigation potential per sector for a cut-off costlevel of $100 \mathrm{US} \$ / \mathrm{tCO}_{2} \mathrm{e}$ [38]. The reduction potential per sector were based on literature review. This is defined as the "technical potential that is economically attractive from a social perspective". Although all emitting sectors were part of the analysis, here the focus is on the energy demand sectors, industry, buildings and transport. The study present an in depth overview of measures to reduce the sectoral emissions. These are compared to the current policies scenario of the international agency's world energy outlook [39]. The IAM results are compared to this specific study because (1) it examines mitigation potential of all three demand sectors in a comparable manner, (2) this calculated avoided emission potential was based on a thorough examination of the literature focussing on sector and technology detail, and (3) it is recent analysis and therefore state of the art. In the supplementary materials a comparison between the UNEP GAP baseline emissions to the IAM baseline emissions can be found. The table below indicates for each sector the estimated potentials per technological measures for the three demand sectors. The sectoral aggregate potential is corrected for interaction effects.

\section{Results}

\subsection{Baseline developments}

Fig. 1 shows the baseline sectoral $\mathrm{CO}_{2}$ emissions of the four IAMs, 

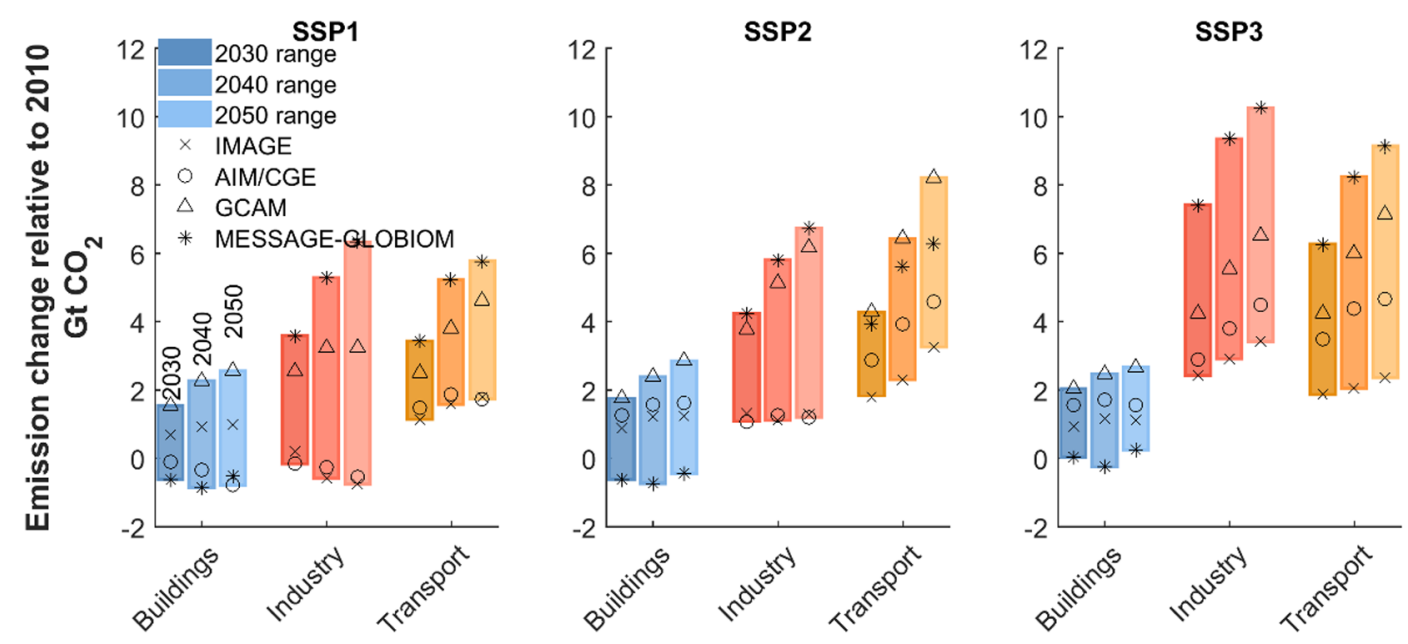

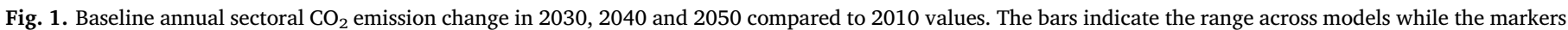
show the model specific results.

three sectors and three SSPs. The Figure shows first of all that there is a considerable range across the models, but also that there are significant differences across the SSPs. Across models there is large uncertainty in the industry and transport sector baseline future emissions development, shown by the wide range that these sector emissions increases span. This is most pronounced in SSP3 where emissions in 2050 range from 1.4 to 2.2 and 1.3 to 2.6 times 2010 values, in respectively the industry and transport sector. In SSP3 and SSP2, transport and industrial emissions are projected to increase in all models, while buildings emissions stay closer to current values. In an SSP1 world, the assumed technological progress and sustainable consumption trends would lead the transport and industry sectors in IMAGE and AIM/CGE to emit close to current direct annual emissions, while MESSAGE and GCAM show still considerable growth of emissions in these sectors.

Fig. 2 shows the contribution of the factors population growth, final energy per capita, electrification and fuel switching to the change in emissions per sector and per scenario (results of the decomposition). In all three sectors and scenarios, population and final energy consumption per capita continue to increase which leads to higher direct emissions, while electrification leads to lower direct emissions. In transport and industry the projected emission ranges across the models can largely be attributed to uncertainty in the final energy per capita development as well as fuel content. Note here that in those models where the sector continues to be more carbon intensive, the effect of increased final energy demand will be larger as well. In the buildings sector, the largest contributor to cross-model uncertainty lies in the types of fuel used. Currently many households are dependent on traditional biomass ( $40 \%$ of global population), mostly used for cooking in developing countries [24]. Models differ with respect to the question whether this trend will continue or alternatively whether a shift to cleaner fuels will take place.

In all three baselines the sectors experience an autonomous electrification trend. In the buildings sector this trend is the most apparent and robust across models and scenario's. This is in line with recent developments with electricity-based applications, like appliances and air-conditioning, associated with higher affluence, are growing faster than fuel-based applications, like space heating and cooking. Moreover, electricity is expected to be subject to a slower cost increase than other carriers. In both transport and industry sectors, which are currently largely dependent on fossil fuels, some electrification occurs. In SSP2, for example, the share of electricity use in transport varies between 3 and $10 \%$ compared to $1 \%$ in 2010 . Fuel shifting shows diverging effects on emissions. $\mathrm{CO}_{2}$ emissions can decrease due to higher biomass or natural gas shares, or increase for example due to use of fossil synfuel for transportation.
A clear difference across scenarios is the projected level of electrification, leading in SSP1 to slightly lower emissions, and population growth, leading in SSP2 and SSP3 to higher emissions. Increased population growth has a larger effect on transport and industry emissions than on buildings emissions as these sectors are more emission intensive per capita, particularly in SSP3. The building sector, in fact, acts rather similar up to 2050 across the scenarios. Fuel content is generally less carbon intensive in the SSP1 sustainability world. While differences can be seen in final energy per capita across scenarios, these differences are more pronounced across models than scenarios.

\subsection{Mitigation scenarios}

Fig. 3 compares the projected sectoral emissions of a stringent climate scenario $\left(2.6 \mathrm{~W} / \mathrm{m}^{2}\right.$ for SSP1 and SSP2, and $3.4 \mathrm{~W} / \mathrm{m}_{2}$ for all three scenarios) to the SSP baseline emissions. The difference between the baseline and mitigation scenarios indicates the sectoral avoided emissions. The industry and transport sectors show the highest avoided direct emissions as these two sectors have also grown the most compared to 2010 values. In SSP3 the industry emissions in the mitigation scenario go significantly beyond 2010 levels. In this scenario, the higher system emissions (also beyond the demand sectors) compared to the SSP1 sustainable case, means that eventually stronger emission cuts are required. The models see more potential to achieve these required reductions in the industry sector. A similar effect can be seen when comparing the $3.4 \mathrm{~W} / \mathrm{m}^{2}$ to the $2.6 \mathrm{~W} / \mathrm{m}^{2}$ case, where the additional emission reduction effort required largely occurs in the industry sector. In all models the industry sector in this case needs to reduce its emissions with 5Gt or more by 2050 in SSP2. The buildings sector is projected to have a lower direct emission reduction potential. This can partly be explained by its large electricity share in the baseline, therefore emitting less direct emissions. Buildings electrification levels are projected to increase further to $45-60 \%$ (model range) in 2050 under $2.6 \mathrm{~W} / \mathrm{m}^{2}$ assumptions in the SSP2 scenario compared to $43-49 \%$ under no climate policy assumptions.

Fig. 4 shows that the large emission reduction taking place in the industry sector are for the largest part the result of reduced fuel content of the non-electric energy. In the transport and buildings sector, with the exception of transport in SSP3, the contribution of final energy reduction and fuel content to emission reduction are more comparable. It is notable that electrification in both sectors plays a smaller role. In the transport sector electrification is subjective to behavioral change, and also limited to certain modes and distances travelled, which could constrain this potential. Moving from $3.4 \mathrm{~W} / \mathrm{m}^{2}$ to a $2.6 \mathrm{~W} / \mathrm{m}^{2}$ target pushes the level of electrification in transport especially in 2050, while 

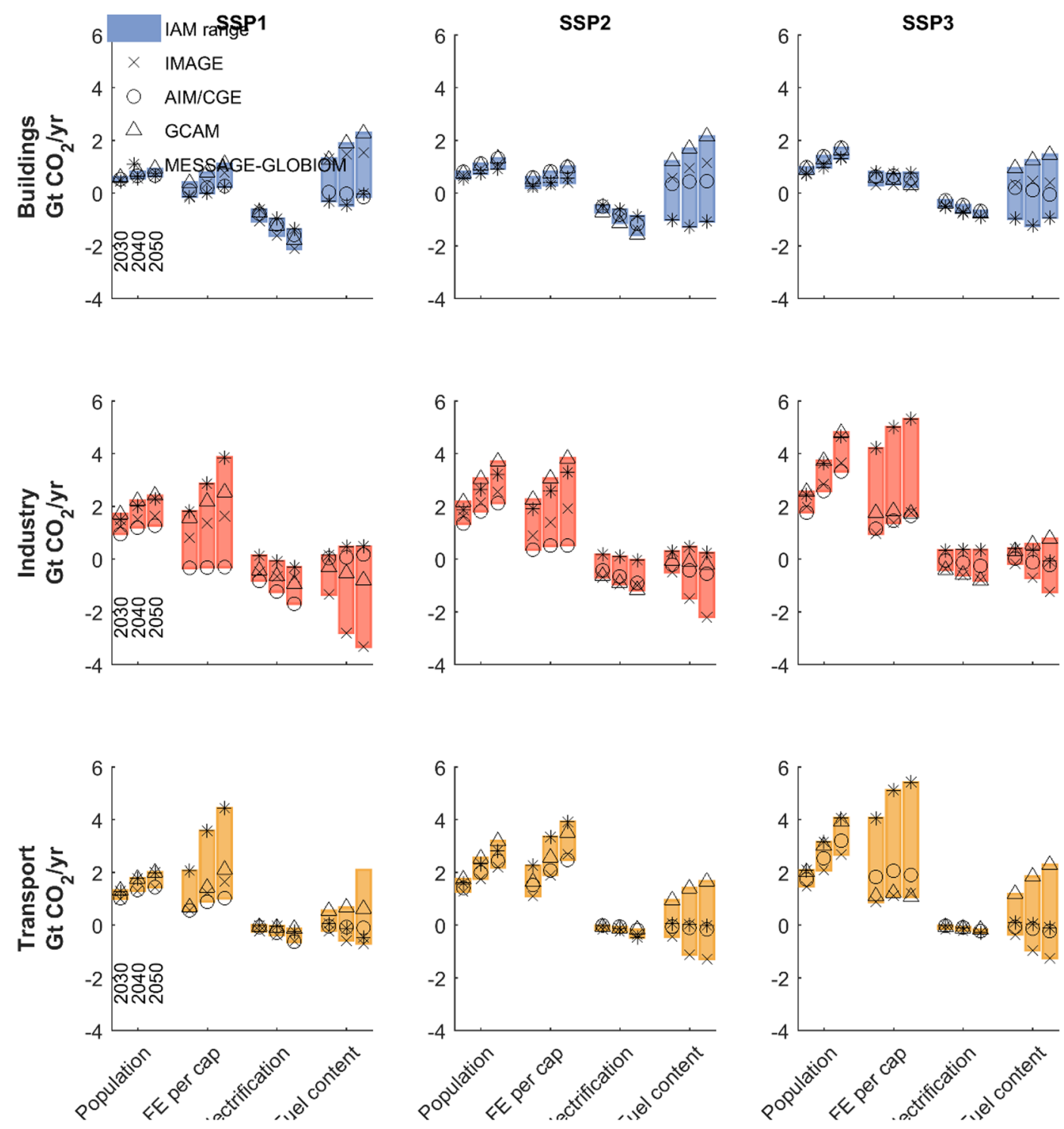

Fig. 2. Decomposition of direct carbon emissions per end use sector in the baseline scenario compared to 2010 values. This figure shows for each sector how population, final energy per capita, electrification (Electrification refers to share of electricity and hydrogen), or shifting to less or more carbon intensive fuels for the remaining non-electric final energy shares contribute to increasing emissions (positive values) or decreasing emissions (negative values) in 2030,2040 and 2050 (compared to 2010). The different markers indicate the model specific values.
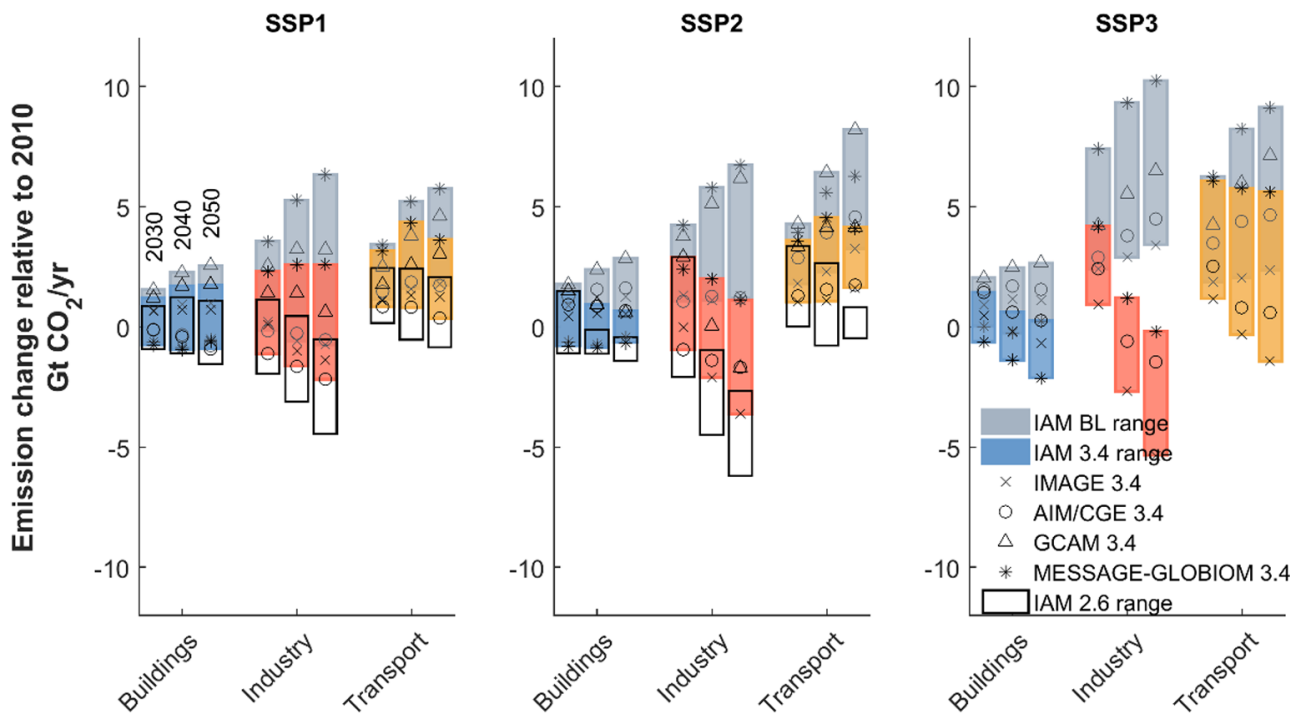

Fig. 3. Annual sectoral $\mathrm{CO}_{2}$ emission change in 2030, 2040 and 2050 compared to 2010 values in a mitigation pathway (2.6 $\mathrm{W} / \mathrm{m}^{2}$ for SSP1 and SSP2, and $3.4 \mathrm{~W} / \mathrm{m}^{2}$ for all three scenarios). In grey the baseline scenario results are depicted, and the difference between mitigation an baseline values correspond to the avoided carbon emissions. The bars indicate the range across models while the markers show the model specific results. 


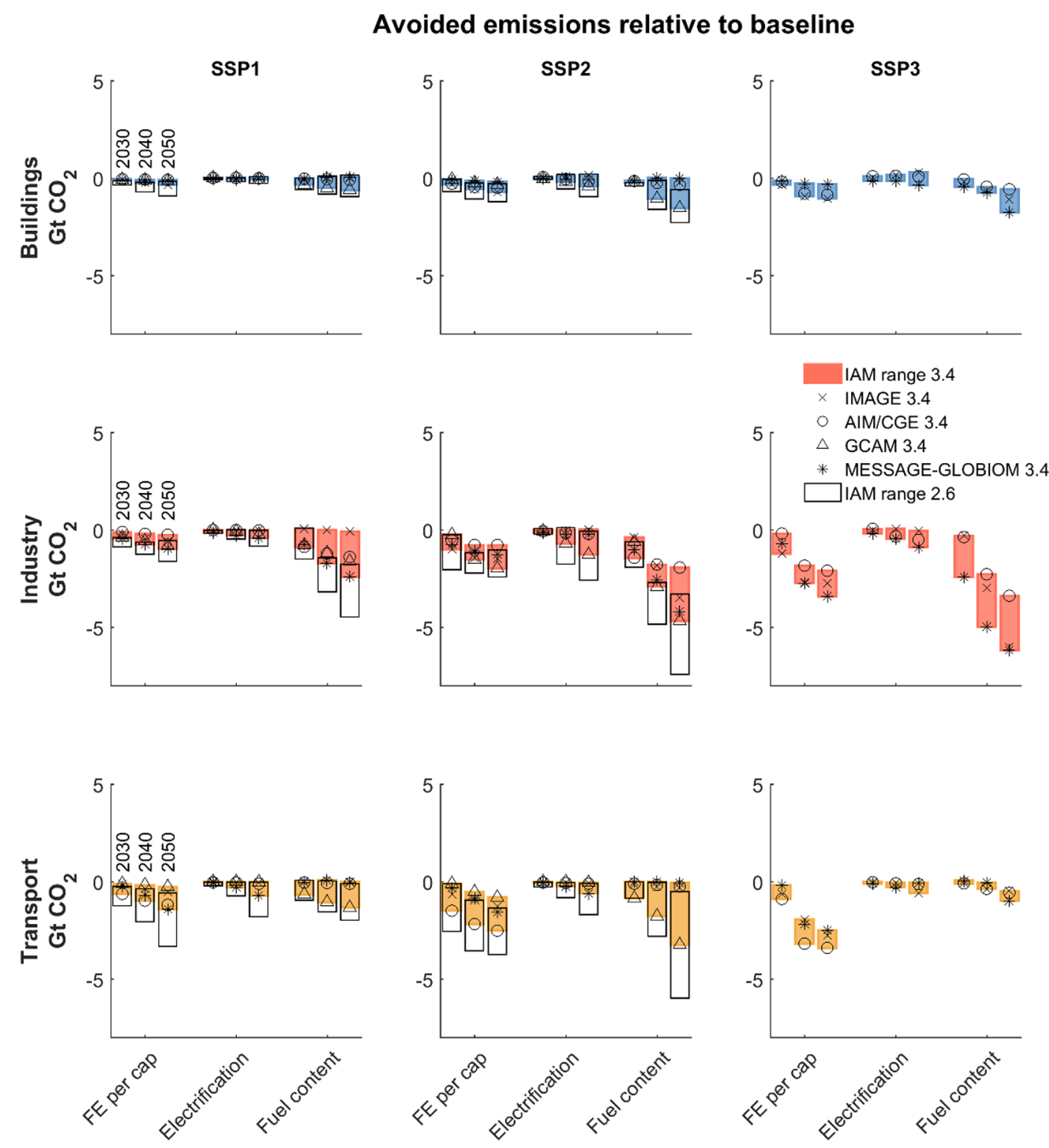

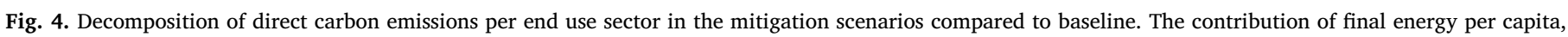
electrification, or shift to less carbon intensive fuels for the remaining non-electric final energy shares to emission reduction in 2030,2040 and 2050 is shown. GCAM SSP3 scenarios couldn't meet a $3.4 \mathrm{~W} / \mathrm{m}^{2}$ mitigation target and is therefore excluded from the SSP 3 mitigation comparison.

energy efficiency improvements are adopted faster, i.e. larger emission reduction can be seen already in 2030 , in response to a stricter mitigation target.

On average between models and across scenarios, comparing the contribution of the three components, the model results show that fuel switching in the models can lead to the most drastic emission reductions in a short time frame, while energy efficiency improvements have a robust and substantial role in emission reduction as well.

\subsection{Energy service growth compared to energy efficiency}

This section takes a deeper dive to energy efficiency and service demand change affecting final energy requirements in the GCAM and IMAGE projections of passenger transport, freight transport and buildings. Compared to the other models GCAM and IMAGE can both be characterised as more bottom-up, with relatively high amount of detail in their transport and buildings sector representation.

Globally the demand for energy service per capita is projected to continue to grow in all three sectors and scenarios in IMAGE and GCAM (see Fig. 5). The only exception to this is the transport passenger kilometre demand in GCAM in SSP3, which stagnates after 2030. Interestingly, while in IMAGE the increased service demand in the transport sector is expected to contribute to a larger increase in energy demand per capita than in the freight sector, in GCAM this is the other way around. In turn, in IMAGE this high service demand increase is compensated with higher expected energy efficiency gains compared to GCAM. In both IMAGE and GCAM in the passenger transport sector the demand growth is related to increasing income. The increase of demand with rising income levels off due to the amount of time that a person can spend travelling, limited by the speed of transport modes [15]. Therefore, while the structure of the two models is rather similar, the varied levels of passenger kilometre growth will be the result of how sensitive this growth is to income change and where saturation level lies. While in SSP1 for example IMAGE annual per capita transport passenger kilometres globally grows to 14.400 per year, GCAM projections show a slower growth with 11.400 annual pkm's per capita in 2050.

Compared to SSP2, the lower SSP1 transport final energy per capita 

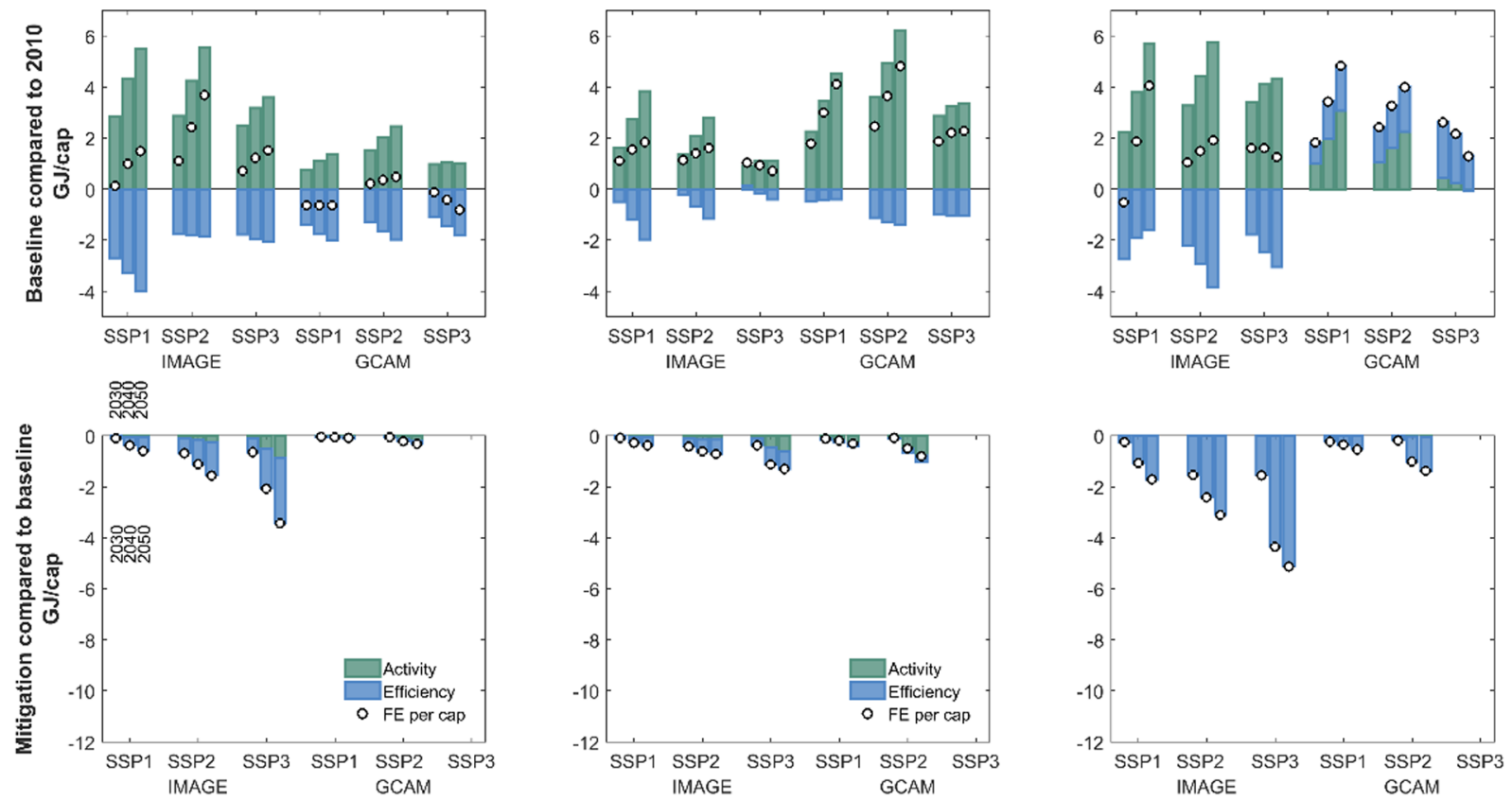

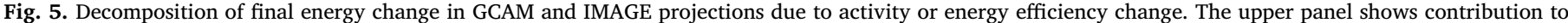

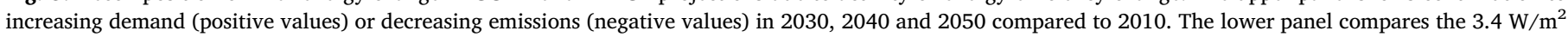

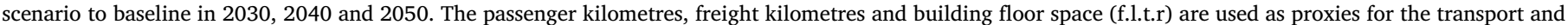
buildings energy service.

is mainly the result of energy efficiency improvements, while in SSP3 there is a slower growth of service demand. The more "sustainable" behavior in SSP1 thus is more the result of energy effiency improvements, such as modal shift and adopting energy efficient vehicles, than reduced travelling. In the building sector in GCAM the energy used per service demand increases, possibly due to higher appliances and aircondition use. In reaction to the implemented carbon tax the IMAGE model shows higher efficiency response than GCAM in both transport and buildings. This improved energy efficiency is additional to the baseline improvements. Both models show that in the climate policy scenarios the reduction of passenger transport final energy is largely the effect of improved energy efficiency, and less activity reduction. In the freight sector, the contribution of energy efficiency is relatively small, while the service demand does respond in both models to the increased cost of travelling due to the carbon tax implementation.

\subsection{Emission reduction potentials 2030}

Table 3 compares the SSP2 the avoided emissions under a $2.6 \mathrm{~W} / \mathrm{m}^{2}$ pathway to the emission reduction potentials of the technology oriented assessment. Based on the in depth literature review the study sees high potential for improved energy efficiency standards in new buildings, thermal retrofit of existing buildings (see also Table 2). In comparison the energy efficiency improvement in the IAMs is significantly lower. A reason for this could be that improved insulation is not explicitly represented, as some of the IAMs focussing more on energy producing technologies, as was discussed in the methods. Another reason for this could be the increased electrification in the IAM building sector. Finally, a reason could be the relatively short time frame of 2030 . The technical assessment assumes all new buildings to be near-zero from 2020 onwards in OECD countries and in non-OECD from 2020 to 2025. The models do not anticipate such rapid changes in energy efficiency, but shows significantly higher energy efficiency improvements in 2040 and 2050 than in 2030. The higher energy efficiency potential identified in the short term by the technology oriented assessment, would reduce the pressure on the long-term, which has been stressed also by $1.5{ }^{\circ} \mathrm{C}$ focussed studies [40], however the question remains whether indeed these policies can be implemented at such a rapid scale.

The technology oriented assessment also sees very high energy efficiency reduction potential in the transport sector for light duty vehicles, heavy duty vehicles, shipping and aviation. While energy efficiency in the transport sector is important to decarbonise emissions in the IAM results, it is substantially lower than the potential indicated by the bottom up study (0.9-2.7 Gt compared to 4.1-5.3 Gt). Possibly the limited modal shifts in IAM projections, and electric vehicle adoption in the short term, as was found by Edelenbosch et al. [15] explains this difference. Also, this could be explained by the smaller freight sector energy efficiency response of GCAM and IMAGE, compared to the potential indicated for shipping and heavy duty vehicle by the technical assessment. While the industrial emissions reductions required in the IAM mitigation scenario are in size comparable to the bottom-up analysis indicated potential, the IAMs rely more heavily on rapid fuel switching while the bottom study sees highest opportunities in energy efficiency improvement. A similar effect between sectoral studies and IAM results was also reported in the IPCC $1.5{ }^{\circ} \mathrm{C}$ report. In general, the comparison shows that there is a high technical potential to further improve energy efficiency in the short term most notably in the transport sector and buildings sector, compared to the IAM projected mitigation strategies.

\section{Discussion}

The analysis leads to a number of conclusions with respect to the IAM projections. A number of caveats, however, need to be kept in mind.

\subsection{Focus on aggregated and global results}

In this paper model results have been discussed at the global level while underlying regional developments will contribute to the observed trends. Increased energy service demand does not imply that in all regions service demand increases; in certain regions it may grow rapidly while in others a certain saturation level is reached. Therefore, it would be interesting to look at the regional trends - and also to analyse how 
Table 2

Overview of $\mathrm{CO}_{2}$ emission reduction potentials per demand sector. Indirect emissions are emissions that are caused by the electricity use in the sector.

\begin{tabular}{|c|c|c|c|c|}
\hline Sector & Category & $\begin{array}{l}\text { Emission reduction potential in } \\
2030\left(\mathrm{GtCO}_{2} \mathrm{e}\right)\end{array}$ & Emissions category & $\begin{array}{l}\text { Sectoral aggregate potential, corrected for overlap } \\
\text { between measures }\left(\mathrm{GtCO}_{2} \mathrm{e}\right)\end{array}$ \\
\hline \multirow[t]{6}{*}{ Buildings } & New buildings & $0.68-0.85$ & \multirow[t]{4}{*}{ Direct } & \multirow[t]{6}{*}{$1.6-2.1$} \\
\hline & Existing buildings & $0.52-0.93$ & & \\
\hline & Renewable heat - bio-energy & 0.39 & & \\
\hline & Renewable heat - solar energy & 0.21 & & \\
\hline & Lighting & 0.67 & \multirow[t]{2}{*}{ Indirect } & \\
\hline & Appliances & 3.3 & & \\
\hline \multirow[t]{4}{*}{ Manufacturing Industry } & Energy efficiency - indirect & 1.9 & \multirow{4}{*}{$\begin{array}{l}\text { Indirect } \\
\text { Direct }\end{array}$} & \\
\hline & Energy efficiency - direct & 2.2 & & \multirow[t]{3}{*}{ 2.1-3.3 (incl. CCS 3.3-4.6) } \\
\hline & Renewable heat & 0.5 & & \\
\hline & CCS & 1.22 & & \\
\hline \multirow[t]{5}{*}{ Transport } & HDV potential (efficiency, modal shift) & 0.88 & \multirow[t]{5}{*}{ Direct } & \multirow[t]{5}{*}{$4.1-5.3$} \\
\hline & $\begin{array}{l}\text { LDV potential (efficiency, modal shift, } \\
\text { electric vehicles) }\end{array}$ & 2.0 & & \\
\hline & Shipping efficiency & 0.7 & & \\
\hline & Aviation efficiency & $0.32-0.42$ & & \\
\hline & Biofuels & $0.63-0.81$ & & \\
\hline
\end{tabular}

Table 3

Comparison of average avoided $\mathrm{CO}_{2}$ emissions in the IAMs under a SSP2 $2.6 \mathrm{~W} /$ $\mathrm{m}^{2}$ pathway in $\mathrm{Gt}$ with the $\mathrm{CO}_{2}$ emission reduction potentials found in the sector-by-sector analysis bottom up analysis. The negative sign in the ranges indicates increased emissions instead of avoided.

\begin{tabular}{llll}
\hline & Buildings & Industry & Transport \\
\hline IAM total sector & $0.7(0.3-1.0)$ & $2.6(0.9-3.2)$ & $1.7(0.9-2.7)$ \\
IAM eff & $0.4(0.0-0.7)$ & $1.1(0.2-2.0)$ & $1.3(0.0-2.5)$ \\
IAM electrification & $0.0(-0.1$ to & $0.0(0.0-0.2)$ & $0.0(0.0-0.3)$ \\
& $0.0)$ & & \\
IAM fuel switch & $0.3(0.2-0.4)$ & $1.4(0.6-1.9)$ & $0.3(0.0-0.8)$ \\
Technology-oriented & $1.6-2.1$ & $2.1-3.3($ incl. CCS & $4.1-5.3$ \\
$\quad$ assessment & $1.2-1.8$ & $3.3-4.6)$ & \\
BU eff & & $1.6-2.8^{1}$ & $3.4-4.5$ \\
BU electrification & $0.4-0.8$ & $0.4-0.6+0.9-1.5$ & $0.6-0.8$ \\
BU fuel switch & & $(\mathrm{CCS})$ & \\
& &
\end{tabular}

1 Part of the eff reduction is electrification (about 9\% of cars).

these potentially influence the global trends. Similarly, in SSP2 and even more in SSP3 the emission reduction through final energy per capita change is larger than in SSP1 and increases over time. Whether this is due to energy service demand changes or energy efficiency improvements is not deciphered for all models. The IMAGE and GCAM service demand results show that there is quite some difference between the scenarios in these two component developments.

\subsection{Technology assessment comparison}

When discussing emission mitigation potentials, a clear definition of the baseline scenario is very important. The reference baseline emissions used for the technical assessment projects slightly lower emissions in 2030 in the transport, industry and buildings sector (see Supplementary Materials [41]). This can be explained by the different scenario assumptions: the WEO reference is a current-policies scenario (no changes in policies from mid-2016 onwards), while the SSP2 baseline is a scenario without climate policy.

Although the 2030 IAM avoided emissions in a $2.6 \mathrm{~W} / \mathrm{m}^{2}$ scenario are not directly comparable to the 2030 technical potential, the comparison still gives some interesting insights. First of all- in spite of the baseline emissions of the technical potential study being lower - their analysis shows that there is more room for emissions reductions in the short term than projected by the models. Secondly, it could be said that at least the required emission reduction to meet the $2.6 \mathrm{~W} / \mathrm{m}^{2}$ are not larger than the technical potential. Note that however that this is at the global level while at the regional level differences may exist. On the other hand it shows also that demand sector emissions could be reduced further - already in the short term. Comparing the types of improvements that are expected to have the largest effect on emissions it is clear that while the models see faster and larger reduction through fuel switching, the bottom up study shows higher gains through energy efficiency improvements. It is these energy efficiency improvements in particular in the buildings and transport that could enhance the demand sector potential compared to current model projections.

\section{Conclusions}

Projecting global emissions from energy demand over the coming century comes with many uncertainties. Conforming to a stringent mitigation target leads less room for total emission ranges than in a baseline, but sectoral efforts and the underlying strategies to achieve this target can widely differ across models and scenarios, depending also on baseline assumptions. This multi-model, multi-scenario, and multi-sector study of IAM projections distils robust trends across the demand sectors developments while disentangling the key underlying uncertainties, that should be further explored.

Robust findings across scenarios and models are:

Model-based projections show that baseline emissions can grow rapidly in the industry and transport sectors in coming decades, but this highly uncertain across models. The model range is most pronounced in SSP3 where emissions in 2050 range from 1.4 to 2.2 and 1.3-2.6 times 2010 values, in respectively the industry and transport sector. The SSP3 scenario shows the highest increase for industrial emissions (on average $6 \mathrm{Gt} \mathrm{CO}_{2}$ increase in 2050) and SSP2 for the transport sector (on average $5.5 \mathrm{Gt}$ increase in $\mathrm{CO}_{2}$ ). Clearly, this range has a huge impact on the mitigation effort, expressed in sectoral avoided emissions, to comply to stringent climate policy. An improved understanding of future demand growth in these sectors is therefore the next key step for modellers to better inform policy on the effort and measures required in the demand sectors to reduce emissions.

Decomposition analysis shows that key uncertainty across models is the growth of final energy per capita over the coming decades, determining the sector's carbon emissions. This finding is in line with a recent published study testing the sensitivity of the SSPs $\mathrm{CO}_{2}$ emissions to key drivers characterizing the scenarios. They find that economic growth and energy intensity assumptions, together forming the final energy per capita, are the most important uncertainties. This is also associated with the possible presence of demand service saturation levels, which was demonstrated by the different levels of service demand increase by GCAM and IMAGE. In 
addition, the comparison between IMAGE and GCAM show varying levels of energy efficiency development, related to the foreseen technological change.

Based on this finding, for modellers the key challenge is to better understand the uncertainty surrounding energy efficiency and service demand projections. Currently services demand projections are rather unresponsive while the cross model comparison indicates that they: 1) can largely impact future emissions, and 2) are highly uncertain. Understanding drivers of service demand can give a better sense of what to expect of the future, while also allowing to evaluate policy measures impacting the relation between the drivers and service demand. An example can be transport and housing demand, impacted by urbanization and city infrastructure.

The SSP scenarios show that the sectoral growth and the technology development have a large effect on the sectors mitigation challenge, but currently are not evaluated as active climate change policy measures. Certain demand side developments assumed by SSP1, such as like increased technology development affecting energy efficiency or car sharing and material recycling to reduce energy service demand, effectively reduce energy requirements, can be affected by policy. However, these changes show little response to cost effective emission mitigation, generally implemented in IAMs through a carbon tax. A next interesting step would be to design scenarios in which policies affecting demand sector developments are explicitly evaluated as an mitigation measure to better assess the effects of targeted demand sector policies. The technical assessment shows that in the short term there is more room for energy efficiency improvements, particularly in the transport and buildings sector, than accounted for in the IAM middle of the road $2{ }^{\circ} \mathrm{C}$ scenarios. From the technical perspective considerable additional demand-side emissions reduction could be achieved in all three sectors through energy reduction. This is most apparent in the transport and buildings sector, where improved insulation, higher electric vehicle penetration rates, modal shift and energy efficiency improvements in the freight sector could reduce final energy demand to lower levels in the short term than currently projected. While in the IAM projections energy efficiency is projected to have a robust and continuous role, fuel switching levels can be pushed rapidly to higher levels in a relatively short time. Especially the industry sector is projected to be able to reduce emissions quickly, largely as an effect of fuel switching. Possibly, consideration of the energy efficiency improvements suggested by the technical assessment would remove the pressure of the drastic and fast fuel switching required in the current IAM projections to meet the set climate goals.

\section{Acknowledgements}

D. van Vuuren's contribution benefited from funding from the European Commission for the REINVENT project (grant agreement 730053 - Horizon 2020). The research leading to these results has received funding from the European Research Council under the European Union's Seventh Framework Programme (FP7/2007-2013)/ ERC grant agreement no. 336155 - project COBHAM "The role of consumer behaviour and heterogeneity in the integrated assessment of energy and climate policies". S. Fujimori's contribution benefited from funding from the the Environment Research and Technology Development Fund (2-1908) of the Environmental Restoration and Conservation Agency of Japan and JSPS KAKENHI Grant Number $19 \mathrm{H} 02273$.

\section{Appendix A. Supplementary material}

Supplementary data to this article can be found online at https:// doi.org/10.1016/j.apenergy.2019.114347.

\section{References}

[1] Fais Birgit, Sabio Nagore, Strachan Neil. The critical role of the industrial sector in reaching long-term emission reduction, energy efficiency and renewable targets. Appl Energy 2016;162:699-712.

[2] Kriegler Elmar, et al. The role of technology for achieving climate policy objectives: overview of the EMF 27 study on global technology and climate policy strategies. Clim Change 2014;123(3-4):353-67.

[3] Krey Volker, Luderer Gunnar, Clarke Leon, Kriegler Elmar. Getting from here to there-energy technology transformation pathways in the EMF27 scenarios. Clim Change 2014;123(3-4):369-82.

[4] IPCC. Energy Systems. In: Climate Change 2014. Contribution of Working Group III to the Fifth Assessment Report of the Intergovernmental Panel on Climate Change. Vol. 3. Fifth Asse. NY, USA: Cambridge University Press, Cambridge, United Kingdom and New York; 2014.

[5] IPCC. Summary for Policymakers. In: Global Warming of $1.5^{\circ} \mathrm{C}$. An IPCC Special Report on the Impacts of Global Warming of $1.5^{\circ} \mathrm{C}$ above Pre-Industrial Levels and Related Global Greenhouse Gas Emission Pathways, in the Context of Strengthening the Global Response To; 2018.

[6] Luderer $\mathrm{G}$, et al. Residual fossil $\mathrm{CO}_{2}$ emissions in $1.5-2{ }^{\circ} \mathrm{C}$ pathways. Nat $\mathrm{Clim}$ Change 2018;8(7):626-33.

[7] GEA. Global Energy Assessment: Toward a Sustainable Future. Cambridge, UK, and Laxenburg, Austria: Cambridge University Press and the International Institute for Applied Systems Analysis; 2012.

[8] Rao Shilpa, et al. A multi-model assessment of the co-benefits of climate mitigation for global air quality. Environ Res Lett 2016;11(12):124013-24.

[9] Creutzig Felix, et al. Towards demand-side solutions for mitigating climate change. Nat Clim Change 2018;8(4):268-71.

[10] Krey Volker. Global energy-climate scenarios and models: a review. Wiley Interdisciplinary Rev: Energy Environ 2014;3(4):363-83.

[11] Sugiyama Masahiro, et al. Energy efficiency potentials for global climate change mitigation. Clim Change 2014;123(3-4):397-411.

[12] Marangoni Giacomo, et al. Sensitivity of projected long-term CO2 emissions across the shared socioeconomic pathways. Nat Clim Change 2017;7(2):113.

[13] ONeill Brian C, et al. A new scenario framework for climate change research: the concept of shared socioeconomic pathways. Clim Change 2014;122(3):387-400.

[14] van Vuuren Detlef P, et al. The shared socio-economic pathways: trajectories fo human development and global environmental change. Global Environ Change 2017;42:148-52.

[15] Edelenbosch OY, et al. Decomposing passenger transport futures: comparing results of global integrated assessment models. Transp Res Part D: Transp Environ 2017;55:281-93.

[16] Edelenbosch OY, Kermeli K, et al. Comparing projections of industrial energy demand and greenhouse gas emissions in long-term energy models. Energy 2017;122

[17] Pietzcker Robert C, et al. System integration of wind and solar power in integrated assessment models: a cross-model evaluation of new approaches. Energy Econ 2017;64:583-99.

[18] Blok Kornelis, Nieuwlaar Evert. Introduction to energy analysis. Routledge; 2016.

[19] Pfenninger Stefan, Hawkes Adam, Keirstead James. Energy systems modeling for twenty-first century energy challenges. Renew Sustain Energy Rev 2014;33:74-86.

[20] Bale CatherineSE, Varga Liz, Foxon Timothy J. Energy and complexity: new ways forward. Appl Energy 2015;138:150-9.

[21] Rogelj Joeri, et al. Paris agreement climate proposals need a boost to keep warming well below 2 C. Nature 2016;534(7609):631.

[22] Tavoni Massimo, et al. Post-2020 climate agreements in the major economies assessed in the light of global models. Nat Clim Change 2015;5(2):119.

[23] Urge-Vorsatz Diana, Petrichenko Ksenia, Staniec Maja, Eom Jiyong. Energy use in buildings in a long-term perspective. Curr Opin Environ Sustain 2013;5(2):141-51.

[24] Nejat Payam, Jomehzadeh Fatemeh, Taheri Mohammad Mahdi, Gohari Mohammad, Majid Muhd Zaimi Abd. A Global review of energy consumption, CO2 emissions and policy in the residential sector (with an overview of the top ten CO2 emitting countries). Renew Sustain Energy Rev 2015;43:843-62.

[25] van Vuuren Detlef P, Edelenbosch Oreane Y, McCollum David L, Riahi Keywan. A special issue on model-based long-term transport scenarios: model comparison and new methodological developments to improve energy and climate policy analysis. Transp Res Part D: Transp Environ 2017;55:277-80. https://doi.org/10.1016/j.trd. 2017.05.003.

[26] Creutzig Felix. Evolving narratives of low-carbon futures in transportation. Transp Reviews 2016;36(3):341-60.

[27] Allwood Julian M, Ashby Michael F, Gutowski Timothy G, Worrell Ernst. Material efficiency: a white paper. Resour Conserv Recycl 2011;55(3):362-81.

[28] Fischedick M, Roy J, Abdel-Aziz A, Acquaye A, Allwood J, Ceron J-P, et al. Chapter 10 - Industry, IPCC Working Group III Contribution to AR5. Cambridge University Press; 2014.

[29] Dietz T, Vandenbergh MP, Gilligan J, Gardner GT, Stern PC. Household actions can provide a behavioral wedge to rapidly reduce US carbon emissions. Proc Natl Acad Sci 2009;106(44):18452-6.

[30] van Sluisveld MariësseAE, Martinez Sara Herreras, Daioglou Vassilis, van Vuuren Detlef P. Exploring the implications of lifestyle change in $2 \mathrm{C}$ mitigation scenarios using the IMAGE integrated assessment model. Technol Forecast Soc Chang 2016;102:309-19.

[31] McCollum DL, et al. Improving the behavioral realism of global integrated assessment models: an application to consumers' vehicle choices. Transp Res Part D: Transp Environ 2017;55.

[32] Riahi Keywan, et al. The shared socioeconomic pathways and their energy, land 
use, and greenhouse gas emissions implications: an overview. Global Environ Change 2017:42:153-68.

[33] ONeill, Brian C, et al. The roads ahead: narratives for shared socioeconomic pathways describing world futures in the 21st century. Global Environ Change 2017;42:169-80.

[34] ADVANCE. Model Documentation of Integrated Assessment Model WIKI Platform; 2015. http://www.Fp7-Advance.Eu/Content/Model-Documentation.

[35] JGCRI. GCAM v 5.1 Documentation: Global Change Assessment Model. http:// Jgcri.Github.Io/Gcam-Doc/; 2019.

[36] Stehfest Elke, van Vuuren Detlef, Bouwman L, Kram Tom. Integrated Assessment of Global Environmental Change with IMAGE 3.0: Model Description and Policy Applications. Netherlands Environmental Assessment Agency (PBL); 2014.

[37] Ang Beng W. Decomposition analysis for policymaking in energy: which Is the preferred method? Energy Policy 2004;32(9):1131-9.

[38] Blok, Kornelis, Angélica Afanador, Detlef van Vuuren, Tom Berg, Christian Breyer, et al. Methodology used in Chapter 4-The Emissions Gap Report 2017-Chapter 4-Appendix B. The Emissions Gap Report 2017: A UN Environment Synthesis
Report (2017).

[39] IEA. World Energy Outlook 2016; Paris, France; 2016.

[40] Grubler Arnulf, et al. A low energy demand scenario for meeting the $1.5{ }^{\circ} \mathrm{C}$ target and sustainable development goals without negative emission technologies. Nat Energy 2018;3(6):515-27.

[41] USEPA. Global Anthropogenic Non-CO2 Greenhouse Gas Emissions: 1990-2030. Washington DC; 2012.

[42] Fujimori Shinichiro, et al. SSP3: AIM implementation of shared socioeconomic pathways. Global Environ Change 2017;42:268-83.

[43] Calvin Katherine, et al. The SSP4: a world of deepening inequality. Global Environ Change 2017;42:284-96.

[44] van Vuuren DP, Stehfest E, et al. Energy, land-use and greenhouse gas emissions trajectories under a green growth paradigm. Global Environ Change 2017;42.

[45] Fricko Oliver, et al. The marker quantification of the shared socioeconomic pathway 2: a middle-of-the-road scenario for the 21st century. Global Environ Change 2017;42:251-67. 